\title{
Reliability and Economic Comparison of Ultra-long-distance Transmission Mode
}

\author{
Huaxin Wang, Aiyou Chen", Jian Wang and Yongxi Zhao \\ ShangHai University of Electric Power, Yangpu District, ShangHai, 200090, China \\ ${ }^{*}$ Corresponding author

$$
\begin{aligned}
& \lambda_{S-P}=\sum_{i=1}^{n} \lambda{\underset{s}{m_{i}}}_{i} \\
& \gamma_{s-P}=\frac{\sum_{i=1}^{n} \lambda s_{i}^{m} \gamma_{s_{i}}^{m}}{\sum_{i=1}^{n} \lambda s_{s_{i}}^{m}}
\end{aligned}
$$

Abstract-Combining with the existing transmission technology which is feasible in engineering and theory, four types of ultra-long-distance transmission mode, in terms of UHV AC, UHV DC $( \pm 800 \mathrm{kV}$ and $\pm 1000 \mathrm{kV})$ and Half-wavelength $\mathrm{AC}$ transmission system (HWACT), have been introduced. The reliability and the economy of different modes are compared. Results show that HWACT has obvious advantage in reliability and economy.

Keywords- ultra-long-distance; UHV; reliability; economy

\section{INTRODUCTION}

The ultra-long-distance transmission mode refers to the transmission mode of transportation distance between 2 000 3 $000 \mathrm{~km}$. In recent years, the distance between energy bases and load center increases accordingly. The distance will exceed 2 $000 \mathrm{~km}$ in the future. The interregional, multinational electricity transmission capacity will reach 373 million $\mathrm{kW}$ by 2020[1]. The grid transmission capacity is limited now, which can't afford such massive electricity demand over long distance. Thus developing and researching new ways of transmission is needed to meet the demand of energy development.

The long distance transmission, whether using DC or AC, has been argued for a long time. Combining with the existing transmission technology which is feasible in engineering and theory, UHV, UHVDC and HWACT are suitable for Ultra-long-distance transmission[2-4]. The present research of transmission mode has achieved some results. The [5-8] have calculated the reliability and economic indexes. But it doesn't consider the influence of reactive power compensation equipment during the index calculation of UHV. Meanwhile, the influence of tuning network has not been considered when the electrical distance of HWACT is not enough. The economic index sensitivity of system is also not analyzed. The calculation model is oversimplified.

The paper has analyzed the reliability and economic indexes with the reactive power compensation devices of UHV and the tuning network of HWACT. Finally it obtained reasonable mode of ultra-long-distance transmission power.

\section{RELIABILITY CALCULATION}

The transmission system is composed of a series of components connected through the series-parallel form, so to get the reliability model of series parallel system based on the relationship of each component can be realized. Calculation of power transmission system using the series-parallel connection model can be performed using the formula of reliability:

The formula for series system forced outage rate and forced outage time are as follows:
The formula for parallel system forced outage rate and forced outage time are as follows:

$$
\begin{aligned}
& \lambda_{S_{i} m_{i}} \approx\left[\prod_{j=1}^{m} \lambda_{i j}\right] \cdot \sum_{j=1}^{m} \gamma_{i j} \\
& \gamma_{S_{i}{ }_{i}}^{m_{i}}=\frac{\gamma_{S_{i}{ }^{m_{i-1}}} \cdot \gamma_{m_{i}}}{\gamma_{S_{i}^{m_{i}}}+\gamma_{m_{i}}}
\end{aligned}
$$

where $\lambda$ is forced outage rate of transmission system, the unit is year $^{-1}, \gamma$ is the system forced interruption duration, the unit is hours per year.

\section{A. UHV System Reliability}

UHV is connected with the bus of original $500 \mathrm{kV}$ pivotal substation through 500/1 $000 \mathrm{kV}$ step-up transformer and 1 $000 / 500 \mathrm{kV}$ step-down transformer, then the transmission distance reached $2000 \mathrm{~km}$.

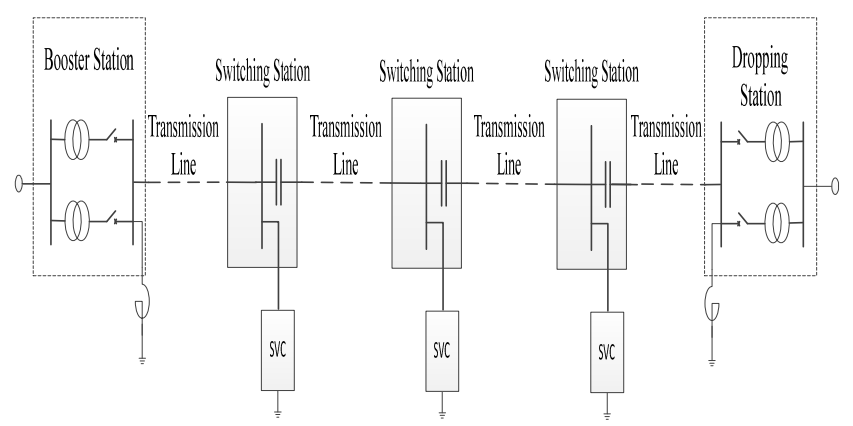

FIGURE I. RELIABILITY CALCULATION MODEL FOR UHV SYSTEM.

The principle and structure of components for UHV and EHV AC power transmission is same, so it can use the existing reliability data of the similar voltage grade ${ }^{[5]}$. Through calculation, the UHV system's forced outage rate is 1.8051 per year when transmission distance is $2000 \mathrm{~km}$, meanwhile, forced interruption duration is 1.618 hours per interruption. 


\section{B. UHV DC Transmission Reliability}

Operation reliability criteria of DC transmission system is calculated according to project.

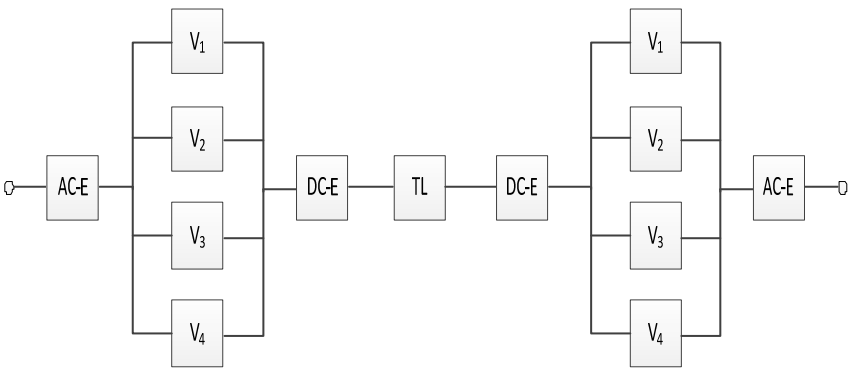

FIGURE II. RELIABILITY CALCULATION MODEL FOR UHV DC SYSTEM.

where AC-E = AC system and auxiliary equipment, including the AC filter or capacitor group and converter transformer; $\mathrm{V}=$ converter valve; DC-E = DC primary equipment, including smoothing reactor and DC filter; TL = DC transmission line.

The reliability data of TL in $\pm 800 \mathrm{kV}$ UHV DC use the overhead line reliability data in UHV . And its reliability index can reference from $85 \%$ of Brazilian $\pm 600 \mathrm{kV}$ HVDC reliability index.

$\pm 800 \mathrm{kV}$ UHV DC system's unipolar forced outage rate is 8.848 year $^{-1}$ and forced interruption duration is $8.937 \mathrm{~h}$ when transmission distance is $2000 \mathrm{~km}$.

Reliability model of $\pm 1000 \mathrm{kV}$ UHV DC is similar with $\pm 800 \mathrm{kV}$ UHV DC. The forced outrage rate of $\pm 1000 \mathrm{kV}$ UHV DC overhead line is $72 \%$ of the $\pm 600 \mathrm{kV}$ overhead lines. It can use $85 \%$ of reliability index of the $\pm 800 \mathrm{kV}$ system to evaluate other classification index.

$\pm 1000 \mathrm{kV}$ UHV DC system’s unipolar forced outage rate is 8.238 year- 1 when transmission distance is $3000 \mathrm{~km}$, and outage time is $7.122 \mathrm{~h}$.

\section{The Reliability of HWACT System}

HWACT is connected with the bus of original $500 \mathrm{kV}$ pivotal substation through step-up transformer and step-down transformer, and the transmission distance reached $3000 \mathrm{~km}$, there is no switching station in lines.

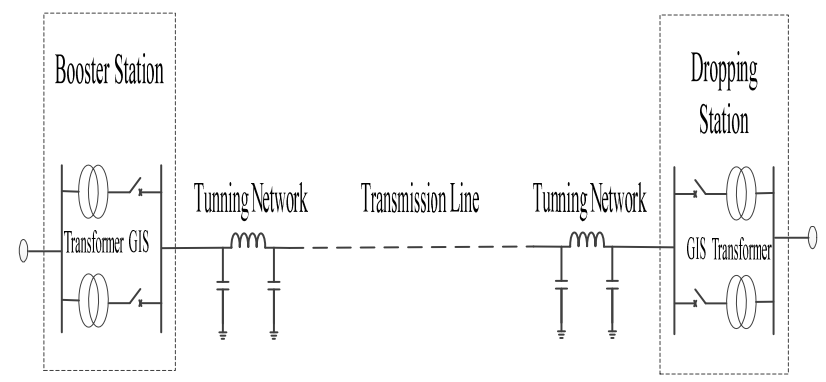

$$
\begin{aligned}
& \text { FIGURE III. RELIABILITY CALCULATION MODEL FOR HWACT } \\
& \text { SYSTEM. }
\end{aligned}
$$

The reliability data of HWACT is same as the UHV. As the components of tuning network is similar to DC equipment (including flat wave reactor and DC filters, etc) of $\pm 1000 \mathrm{kV}$
UHV DC, so the HWACT can use the reliability parameters of the DC part of $\pm 1000 \mathrm{kV}$ UHV DC.

The forced outage rate of HWACT is 2.713 year $^{-1}$ and forced interruption duration is $1.614 \mathrm{~h}$ when transmission distance is $3000 \mathrm{~km}$.

The ideal distance of HWACT is $3000 \mathrm{~km}$, if the transmission distance is less than this length, the system need to use manual tuning network to increase electric distance.

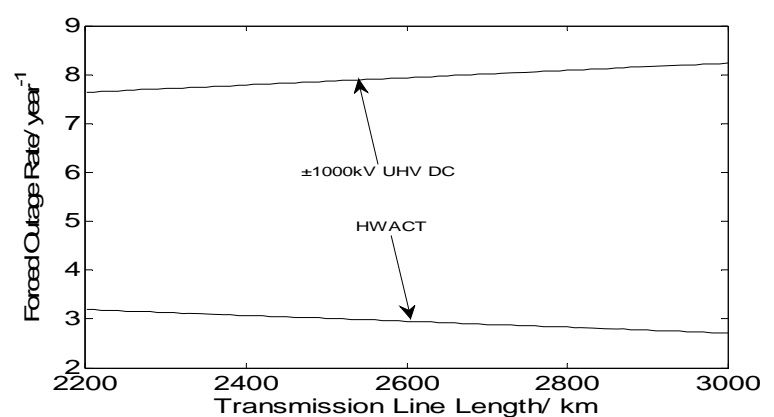

(a) The change of the service rate with distance

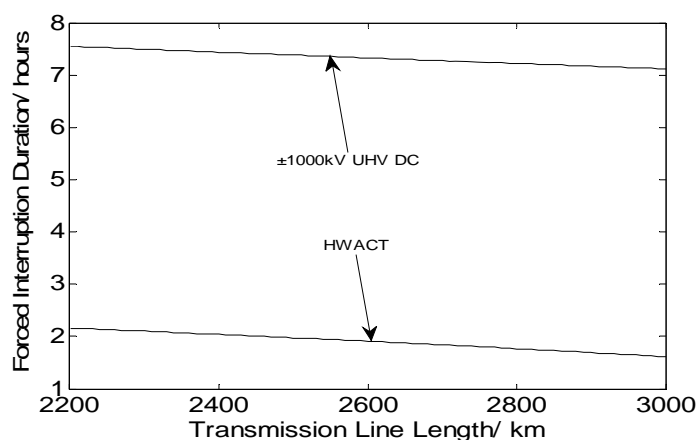

(b) The change of the stoppage time with distance

FIGURE IV.IMPACT OF TRANSMISSION DISTANCE FOR RELIABILITY.

As Figure 7(a) shows, with the increase of transmission distance, $\pm 1000 \mathrm{kV}$ UHV DC forced outage rate increased from 7.639 year $^{-1}$ to 8.238 year $^{-1}$, and HWACT forced outage rate reduced to 2.713 year $^{-1}$ from 3.193 year $^{-1}$. Forced outage rate of $\pm 1000 \mathrm{kV}$ UHV DC increased with the increase of transmission distance increases, while that of HWACT system is reducing. As you can see from Figure 7(b), with the increase of transmission distance, $\pm 1000 \mathrm{kV}$ UHV DC forced interruption duration reduced to $7.122 \mathrm{~h}$ from $7.553 \mathrm{~h}$, meanwhile HWACT system forced interruption duration reduced to $1.614 \mathrm{~h}$ from $2.160 \mathrm{~h}$, so both of them is decreased with the increase of transmission distance.

\section{ECONOMIC COMPARISON}

Economic comparison of ultra-long-distance transmission mode uses Annual Cost Method. The calculation formula of the Annual Cost Method can be written as follows:

$$
N_{F}=\frac{i(1+i)^{n}}{(1+i)^{n}-1}\left\{\sum_{t==_{0}}^{t=m} Z_{t}(1+i)^{m-t}+\left[\sum_{t=l^{\prime}}^{t=m} U_{t}(1+i)^{m-t}+\sum_{t=m+1}^{t=m+n} \frac{U_{t}}{(1+i)^{t-m}}\right]\right\}
$$


where $N_{F}$ is the annual cost, $\boldsymbol{i}$ is the investment recovery rate (discount rate), $n$ is engineering economic life, $m$ is the production time of the project, $t$ is the time parameter of the function, $t_{0}$ is the start time, $t^{\prime}$ is the production time of partial project, $Z$ is the amount of investment, $U$ is the operation cost.

The paper supposed that there is adequate power supply in the sending end and enough load in the receiving end of the system. The calculation formula of the cost delivering unit power is

$$
F_{Y}=\frac{N \quad F}{P}
$$

where $F_{Y}$ is the economic index of power transmission project with the unit $\mathrm{RMB} / \mathrm{kW}$-year, $\mathrm{W}$ is the project static investment with the unit billion RMB, $N_{F}$ is the annual cost with the unit is billion RMB and $P$ the transmission power with the unit MW.

The discount rate is $8 \%$, engineering economic life is 30 years, the maintenance costs of the transformer substation, convertor station and line are respectively $2.2 \%$ and $1.4 \%$ comparing with the total static investment. The power loss is $0.2 \mathrm{RMB} / \mathrm{kW} \cdot \mathrm{h}$. The maximum load utilization hours are 4 500 hours and the number of energy consumption is 3500 hours.

\section{A. The Comparison of UHV and $\pm 800 \mathrm{kV} U H V D C$}

The corona loss of UHV is $10 \mathrm{~kW} / \mathrm{km}$, active loss is $10 \%$ and the line compensation can be considered as the typical parameters. Line active loss of $\pm 800 \mathrm{kV}$ UHV DC is $11.14 \%$, the loss of convertor station at one end of system is $0.7 \%$ rated capacity and the same goes for corona loss.

TABLE I COST COMPARISON BETWEEN UHV AND \pm 800 KV DC TRANSMISSION SYSTEM.

\begin{tabular}{ccccc}
\hline Power Transmission Scheme & $\boldsymbol{P} / \mathbf{M W}$ & W/ Billion RMB & $\boldsymbol{N}_{\boldsymbol{F}} /$ Billion RMB & $\boldsymbol{F}_{\boldsymbol{Y}} /(\mathbf{R M B} / \mathbf{k W} \cdot$ year) \\
\hline UHV AC & 5000 & 15.8063 & 1.6443 & 329 \\
$\pm 800 \mathrm{kV}$ UHVDC & 7200 & 21.2000 & 2.2057 & 306 \\
\hline
\end{tabular}

The conveying unit power comprehensive costs of $\pm 800 \mathrm{kV}$ UHV DC is $6.99 \%$ lower than it of UHV. Under the transmission distance of $2000 \mathrm{~km}, \pm 800 \mathrm{kV}$ UHV DC compared with UHV has obvious advantages in economic aspect.

\section{B. The Comparison of HWACT and $\pm 1000 \mathrm{kV} U H V D C$ System}

The active power loss of line in $\pm 1000 \mathrm{kV}$ UHV DC is

$7.05 \%$. The loss at the system end is $0.7 \%$. Line corona loss is
$10 \mathrm{~kW} / \mathrm{km}$.

HWACT substation uses the hybrid gas insulated switchgear (HGIS). Transmission line adopts double circuit transmission line without switching station. The active and corona loss of line of HWACT are the same as the UHV. Tuning network cost is the same as the equipment cost of DC-E in UHV DC.

TABLE II Cost comparison between $\pm 1000 \mathrm{kV}$ DC and HWACT transmission system.

\begin{tabular}{cccc}
\hline Power Transmission Scheme & $\boldsymbol{P} / \mathbf{M W}$ & $\boldsymbol{W} /$ Billion RMB & $\boldsymbol{N}_{\boldsymbol{F}} / \mathbf{B i l l i o n} \mathbf{R M B}$ \\
\hline $\pm 1000 \mathrm{kV}$ UHVDC & 9000 & 35.5000 & 3.6517 \\
HWACT & 10000 & 30.5494 & 3.2207 \\
\hline
\end{tabular}

The conveying unit power comprehensive costs of HWACT is $20.69 \%$ lower than it of UHV DC. The HWACT has advantages compared to $\pm 1000 \mathrm{kV}$ UHV DC in economic consideration When the transmission distance is $3000 \mathrm{~km}$.

When the transmission line length is shorter than Half-wavelength, appropriate technology should be employed to increase the electrical length up to Half-wavelength.

The economic index is proportional to the transportation distance of HWACT. When HWACT required increasing tuning network to guarantee electric distance, its economy is more obvious.

When the transmission power changed, the economic index of $\pm 1000 \mathrm{kV}$ UHV DC and HWACT system is also changing.

With the increase of transmission power, the economy of both systems also increases accordingly. The economic index of HWACT is always less than $\pm 1000 \mathrm{kV}$ UHV DC, so the economy of HWACT is better than the $\pm 1000 \mathrm{kV}$ UHV DC.

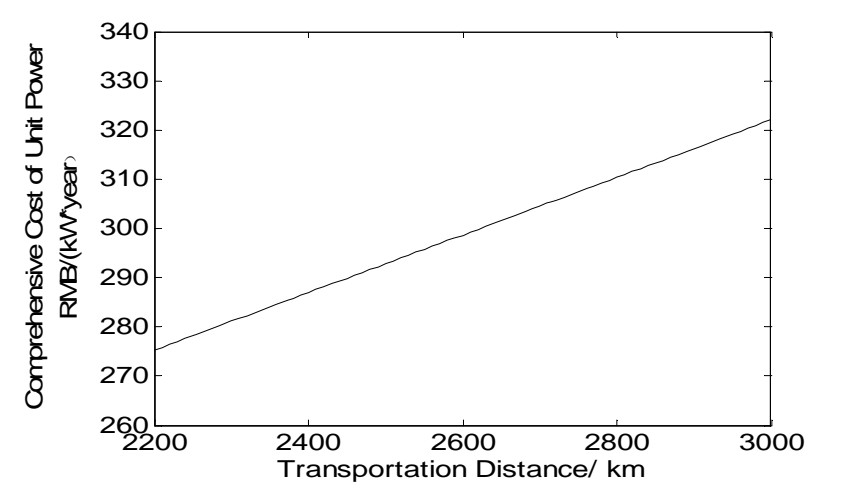

FIGURE V. RELATIONSHIP BETWEEN COST AND DISTANCE FOR HWACT. 


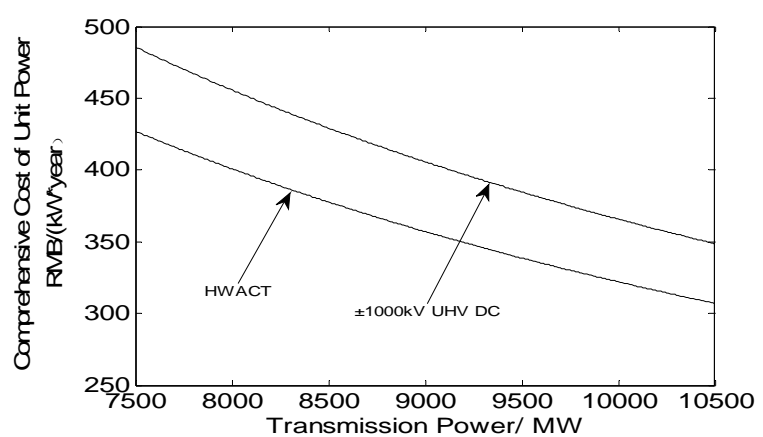

FIGURE VI. RELATIONSHIP BETWEEN COST AND TRANSMISSION POWER FOR HWACT.

\section{CONCLUSION}

(1) Although the reliability of UHV is relatively higher when the transmission distance is between $2000 \mathrm{~km}$ and 2500 $\mathrm{km}$, its limitation should be lower than $2000 \mathrm{~km}$. The reliability of the HWACT is relatively higher between 2500 $\mathrm{km}$ and $3000 \mathrm{~km}$.

(2) In the ultra-long-distance transmission, UHV needs a lot of reactive power compensation equipments and thus its economic performance is not good. In UHV DC, the investment of converter station is large and its comprehensive cost of unit power is relatively high. HWACT system needs less equipments and has better economy.

(3) When the transmission distance is $2000 \sim 2500 \mathrm{~km}$, $\pm 800 \mathrm{kV}$ UHV DC system is better as to the transmission power and the economy index of the system. When the transmission distance is $2500 \sim 3000 \mathrm{~km}$, HWACT system is better in the aspects of transmission power, reliability and economy.

\section{REFERENCES}

[1] LIU Kaijun, GE Xubo, WANG Nan. Energy bases construction and UHV power grid planning [J]. ELECTRIC POWER. 2008, 41(1): 1-3.

[2] WANG Xiuli, SONG Yonghua, WANG Haijun. Development and application of advanced transmission systems [J]. ELECTRIC POWER. 2003, 36(8): 40-46.

[3] WANG Xifan, WANG Xiuli, TENG Yufei. Fractional Frequency Transmission System and Its Applications [J]. Proceedings of the CSEE. 2012, 32(13): 1-6.

[4] Zhou Youging, Yao Jiangang, Peng Jianchun,etal. STUDY OF FOUR PHASE POWER TRANSM ISSION SYSTEM [J]. Proceedings of the CSEE. 1999, 19(5): 80-84.

[5] ZENG Qingyu. Analysis on Reliability of UHVAC and UHVDC Transmission Systems [J]. Power System Technology. 2012, 36(2): 1-6.

[6] SONG Yunting, ZHOU Xiao, LI Bihui, etal. Economic Analysis and Reliability Assessment of UHV Half-wavelength AC Transmission [J]. Power System Technology. 2011, 35(9):1-6.

[7] Zhang Yunzhou. Analysis of economic operation of UHV AC power transmission [J]. China Electrical Equipment Industry. 2007(04): 34-39.

[8] SUN Ke. Economic Analysis on UHV Half-wavelength AC Power Transmission [J]. Power System Technology. 2011, 35(9): 51-54. 